\title{
Grafting Tobacco onto Nutrient-efficient Rootstocks Improves Photosynthesis
}

\author{
Wei Hu, Qing Di, and Jingyi Wei \\ Vegetable and Flower Institute of Chongqing Academy of Agricultural Sciences, Chongqing \\ 401329, China \\ Jie Zhang \\ Nanchang Institute of Technology, Nanchang 330099, China \\ Jia Liu \\ Soil and Fertilizer \& Resources and Environment Institute, Jiangxi Academy of Agricultural \\ Sciences, Nanchang 330200, China
}

AdDitional INDEX words. chlorophyll a fluorescence, potassium, nutrient stress, ribulose diphosphate carboxylase

\begin{abstract}
Potassium deficiency is a major problem limiting tobacco (Nicotiana tabacum) growth, and grafting has the potential to alleviate it. To compare the photosynthetic performance of grafted tobacco under different potassium levels, tobacco Yunyan 87 (main cultivar) and Wufeng No. 2 (potassium high-efficiency cultivar) were selected to conduct mutual grafting trials in the form of hydroculture with two potassium supply levels $\left(5 \mathrm{mmol} \cdot \mathrm{L}^{-1} \mathrm{~K}\right.$ and 0.5 $\mathrm{mmol} \cdot \mathrm{L}^{-1} \mathrm{~K}$ ). The plant growth, gas exchange parameters, chlorophyll $a$ fluorescence, and the initial ribulose-1,5-bisphosphate carboxylase-oxygenase (RuBisCO) activity were measured. The results showed that potassium deficiency could significantly decrease the net photosynthetic rate, stomatal conductance $\left(g_{\mathrm{S}}\right)$, and transpiration rate in the tobacco leaves, resulting in nonstomatal restriction. Grafting could effectively alleviate this problem. The actual quantum yield of photosystem II (PSII) photochemicals in 'Yunyan 87' increased $29.4 \%$ and $20.3 \%$ by grafting, respectively, under normal and low potassium levels. Compared with nongrafted 'Yunyan 87', grafting also effectively improved the electron transfer efficiency of PSII in the tobacco leaves under low potassium stress by reducing nonradiation energy dissipation and enhancing the initial activity of RuBisCO. From this study, it can be known that grafted tobacco plants can improve their photosynthesis by alleviating the nonstomata restriction of leaves under potassium stress and improving the electron transfer efficiency of PSII.
\end{abstract}

Grafting is one method of the propagation of plants. A branch or bud of one plant is grafted onto the stem or root of another so that the two parts joined together and function as a whole plant. Grafting will not only change the ability of tobacco (Nicotiana tabacum) to absorb nutrients, but a series of photoprotective mechanisms, including photorespiration and the mailer reaction, may be influenced by rootstock induction, which is ultimately reflected in a change in the photosynthetic efficiency of the scion. This is a very important factor explaining why grafting is suitable for application under abiotic stress. Grafting experiments on different eggplant (Solanum melongena) rootstock materials showed that low-temperature tolerant eggplant rootstock could reduce the accumulation of reactive oxygen species (ROS) by enhancing the activity of respiratory burst oxidase. Meanwhile, the initial concentration of Ribulose 1,5 bisphosphate (RuBP) was increased to enhance the fixation efficiency of $\mathrm{CO}_{2}$, so as to maintain the higher photosynthesis level of the scion (Gao et al., 2016). Previous research indicated that changes in environmental factors can alter the physiological processes of thylakoid electron

Received for publication 12 Jan. 2021. Accepted for publication 9 Apr. 2021. Published online 2 June 2021.

This work was supported by the China Postdoctoral Science Foundation (Grant No. 2020M673599XB) and Chongqing Postdoctoral Science Foundation (Grant No. cstc2020jcyj-bshX0004).

J.W. is the corresponding author. E-mail: jingyiwei85@163.com.

This is an open access article distributed under the CC BY-NC-ND license (https://creativecommons.org/licenses/by-nc-nd/4.0/). transport, carbon reduction, and $\mathrm{CO}_{2}$ fixation (Allen and Ort, 2001). Under high-photon quantum flux density, the palisade tissue and sponge tissue arrangement of grafted pepper (Capsicum аппиит) are closer than that in self-rooted seedlings (Jang et al., 2014). However, some studies have suggested that grafting does not have a significant effect on the photosynthesis of the scions (Huang et al., 2015; Rahmatian et al., 2014). In a grafting experiment of tomato (Solanum lycopersicum) and potato (Solanum tuberosum), it was found that there was no significant difference in photosynthetic $\mathrm{CO}_{2}$ response between the grafted plants and the control plants when the tomato leaves were measured during the flowering period (Zhang and Guo, 2019).

Potassium cannot only promote the synthesis of chlorophyll in flue-cured tobacco, but also improve the structure of chloroplast, which has an important effect on the photosynthesis of tobacco leaves. At present, the main research on the effect of potassium on plant photosynthesis focuses on three aspects: $g_{\mathrm{S}}$ regulation, mesophyll tissue structure, photosynthetic phosphorylation processes and enzyme activity. For the first aspect of $g_{\mathrm{S}}$, the regulation of $\mathrm{K}^{+}$on stomatal opening and closing is realized by the change in concentration in the guard cells. The signal receptor of this process is $\mathrm{H}^{+}$-ATPase located on the guard cell membrane, which increases the level of $\mathrm{K}^{+}$in the guard cells through the polarization of the $\mathrm{K}^{+}$channel, thus generating cell turgor and promoting stomatal opening (Kim et al., 2010). The close relationship between potassium fertilizer application and $g_{\mathrm{S}}$ also has been verified (Jin et al., 2011; Wang et al., 2012). For the second aspect of mesophyll tissue structure, when 
potassium supply is sufficient, the leaf density decreases, the thickness increases, the ratio of leaf volume to leaf weight decreases, and the gap between the mesophyll tissues becomes larger, which is conducive to the passage of $\mathrm{CO}_{2}$ (Pettigrew, 1999). At the same time, potassium can also increase the gas phase conductance of the mesophyll tissue (Battie-Laclau et al., 2014) and accelerate the decomposition of starch grains in the chloroplasts, which will reduce the transport resistance of $\mathrm{CO}_{2}$ in the chloroplast (Zhao et al., 2001). For the last aspect of photosynthetic phosphorylation processes and enzyme activity, a lack of potassium will not only lead to decreased RuBP activity but also hinder the synthesis of chlorophyll (Weng et al., 2007). Water-soluble small molecules in cells will hinder the supply of inorganic phosphorus and the recycling of RuBP (Gerardeaux et al., 2010). An adequate supply of potassium can promote the decomposition of these small molecules and boost the activity of enzymes in the carbon metabolism system (Quentin et al., 2013).

According to our previous studies, grafting affects the absorption and utilization of $\mathrm{K}^{+}$in tobacco, especially that of a series of strategies for coping with low potassium stress, and also changes the circulation and redistribution pattern of $\mathrm{K}^{+}$in tobacco plants (Hu et al., 2019). This will have a significant impact on the photosynthesis of the tobacco leaves and will directly change the synthesis and transportation of assimilation products. Through the research of gas exchange parameters in grafted tobacco plants and the performance of photosystem II (PSII) electron transfer efficiency under different potassium levels, we hope to clarify the influence and mechanism of grafting on the photosynthesis of tobacco leaves.

\section{Materials and Methods}

Plant materials and grafting treatments. The experiments were conducted in the greenhouse of the Chongqing Academy of Agricultural Sciences, Chongqing, China (lat. $29^{\circ} 36^{\prime} \mathrm{N}$, long. $106^{\circ} 29^{\prime} \mathrm{E}$ ). The main cultivar Yunyan 87 (Yunnan Tobacco Research Institute, Yuxi, China) and K-efficient genotype tobacco 'Wufeng No.2' (Yichang Tobacco Co., Yichang, China) were used in the present research. The industrial quality of the leaf of 'Yunyan 87' is excellent, and the potassium absorption capacity of the root of 'Wufeng No.2' is relatively strong. Using 'Yunyan 87' as the scion and 'Wufeng No.2' as the rootstock thus combines the advantages of the two. The experiment mainly examined the difference between this grafting combination and the nongrafted 'Yunyan 87 '. To ensure the success rate of grafting, the seeds of the rootstock were planted $7 \mathrm{~d}$ before the scion. "Split grafting" was selected as the grafting method once six to eight true leaves had appeared on the seedlings of the rootstock (Ding et al., 2004). In the process of grafting, silicone catheter or a graft clip was used to fix the callus according to the situation of the combination of the rootstock and the scion (Fig. 1). When the new leaves had grown on the grafted plants, the plants were transplanted into a hydroponic box with 12 seedlings per container. The nutrient solution for the hydroponics was formulated as reported in a previous study (Hu et al., 2019). Air pumps were fixed to each container through a hose to supply oxygen to the tobacco seedlings during the experiment. The plants were grown at $22.5^{\circ} \mathrm{C}$ under a $16 / 8$-h light/dark cycle using fluorescent lamps with an average photosynthetic photon flux density $(P P F D)$ of $300 \mu \mathrm{mol} \cdot \mathrm{m}^{-2} \cdot \mathrm{s}^{-1}$ in the greenhouse. The relative humidity ranged from $60 \%$ to $95 \%$.

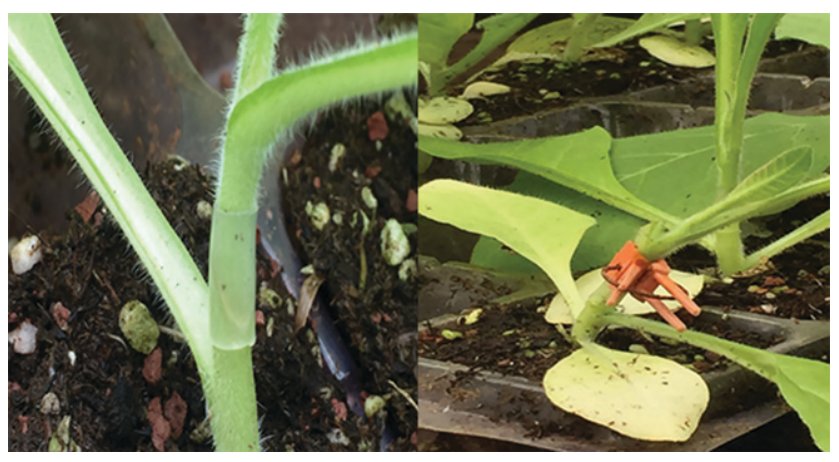

Fig. 1. Silicone catheter or graft clip was used to fix tobacco callus. The left is the silicone catheter and the right is the transplant clip. Split grafting was selected as the grafting method once six to eight true leaves had appeared on the seedlings of the rootstock. In the process of grafting, a silicone catheter or a graft clip was used to fix the callus.

Two $K$ levels were used for the experiments: $+K$, normal supply $\left(5 \mathrm{mmol} \cdot \mathrm{L}^{-1}\right)$ and $-\mathrm{K}$, deficit $\left(0.5 \mathrm{mmol} \cdot \mathrm{L}^{-1}\right)$, using $\mathrm{K}_{2} \mathrm{SO}_{4}$ as the substance source to adjust the $\mathrm{K}$ levels. In addition, four graft treatments ['Wufeng No.2' (W), 'Yunyan 87' (Y), W grafted onto $\mathrm{Y}(\mathrm{W} / \mathrm{Y})$, and $\mathrm{Y}$ grafted onto $\mathrm{W}(\mathrm{Y} / \mathrm{W})$ ] were used in the experiment. Eight treatments were replicated six times with 12 plants in each replicate. The solutions were replaced every $4 \mathrm{~d}$. Tobacco samples were collected $20 \mathrm{~d}$ after the start of the treatment.

Tobacco PLANT GROWTH. The roots, stems, and leaves of the plant samples were separately dried in an oven at $70^{\circ} \mathrm{C}$ for $24 \mathrm{~h}$, and the dry weight was measured with an electronic balance. The penultimate true leaf on the stem of the tobacco seedling was selected as the object of leaf area measurement (LI-3000C; LI-COR Biosciences, Lincoln, NE). Plant height was measured with a leather tape. The root of the sample was carefully rinsed with deionized water, the excess water was absorbed with paper towels, and then the root surface area, root length, and root volume were measured using image analysis software (WinRhizo Pro 2.0; Regent Instruments, Ottawa, ON, Canada).

Determination of the initial activity of RuBisCO. Fresh leaf samples of $0.2 \mathrm{~g}$ were weighed and enzymes were extracted using the method of (Weng et al., 2007). Initial RuBisCO activity was determined using a RuBPcase enzyme-linked immunosorbent assay kit (CK-E91697P; Jinjin Chemical Technology Co., Shanghai, China). The determination method was according to the manufacturer's instructions.

Determination of Leaf gas exchange. Net photosynthetic rate $\left(P_{\mathrm{N}}\right), g_{\mathrm{S}}$, intercellular $\mathrm{CO}_{2}$ concentration $\left(C_{\mathrm{i}}\right)$, and transpiration rate $(E)$ were measured on fully expanded leaves between 8:30 and 10:30 AM using the portable open gas exchange system (LI-6400; LI-COR Biosciences) (Hu et al., 2018). Two blades were measured every day and finished the measurement in $6 \mathrm{~d}$ with little difference in climatic conditions. The environmental parameters during the measurement were as follows: lightemitting diode light source, $P P F D$ of $800 \mu \mathrm{mol} \cdot \mathrm{m}^{-2} \cdot \mathrm{s}^{-1}$, flow rate $500 \mu \mathrm{mol} \cdot \mathrm{s}^{-1}$, chamber temperature $30 \pm 2{ }^{\circ} \mathrm{C}$, and relative humidity $60 \% \pm 1 \%$.

DETERMINATION OF CHLOROPHYLL FLUORESCENCE. The chlorophyll $a$ fluorescence parameters of each grafting treatment were determined on the same leaf used for the gas exchange parameter measurement using a leaf chamber fluorometer (6400-40; LICOR Biosciences). The measurement indicators included 
Table 1. Primers used in real-time fluorescence quantitative reverse transcription polymerase chain reaction (qRT-PCR) analysis. $C A O 1$ is the only gene in the chloroplast that regulates the relative content of chlorophyll $a$ and $b$. HemAl dominates the rate of chlorophyll biosynthesis.

\begin{tabular}{llc}
\hline Gene & Forward primer $\left(5^{\prime}-3^{\prime}\right)$ & Reverse primer $\left(5^{\prime}-3^{\prime}\right)$ \\
\hline CAOl & TGGCCAGAACTAGTCAG & CCTTCCATTAGCCT \\
& TGGATG & TTCCTCTCC \\
HemAl & AAGTGGAATCCC & ACAAGAGAGTCAA \\
& GGTTTCGG & GGCCTGC \\
Actin $^{z}$ & AACAGTTTGGTTGGA & CATGAAGATTAAA \\
& GTTCTGG & GGCGGAGTG \\
\hline
\end{tabular}

${ }^{\mathrm{z}}$ Reference gene for qRT-PCR analysis.

minimum fluorescence yield $\left(\mathrm{F}_{0}\right)$, photochemical quenching coefficient $\left(\mathrm{q}_{\mathrm{p}}\right)$, PSII photochemical maximum quantum efficiency $\left(\mathrm{F}_{\mathrm{v}} / \mathrm{F}_{\mathrm{m}}\right)$, chlorophyll fluorescence nonphotochemical quenching (NPQ), and actual quantum yield of PSII photochemistry $\left(\Phi_{\mathrm{PSII}}\right)$. The specific measurement process and calculation method are the same as in our previous research (Hu et al., 2018).

TOTAL RNA EXTRACTION AND QUANTITATIVE REAL-TIME POLYMERASE CHAIN REACTION. Total RNA was extracted from the leaves of each treatment with TRIzol reagent (Invitrogen, ThermoFisher, Waltham, MA) according to the manufacturer's instructions. Total RNA of $1 \mu \mathrm{g}$ was used to synthesize first-strand complementary DNA in combination with oligo (dT)-18 as a primer and M-MuLV reverse transcriptase (TaKaRa, Kusatsu, Japan). The quantitative real-time polymerase chain reaction (qRT-PCR) (ABI 7900HT; Applied Biosystems, Foster City, CA) was performed in a $20-\mu \mathrm{L}$ reaction system using a LightCycler480 SYBR Green I Master kit according to the protocols. Each sample analysis was repeated at least three times. Primer Premier 5.0 (Premier Biosoft, San Francisco, CA) software was used to design specific primers, and all primers were summarized in Table 1. Each primer possessed high specificity as determined by the melting curve analysis. The polymerase chain reaction (PCR) products were quantified by the $2^{-\Delta \Delta \mathrm{Ct}}$ method (Livak and Schmittgen, 2001).

Statistical analysis. The data in the tables and figures are expressed as the means of all replicates \pm SD. Data were statistically analyzed by analysis of variance using statistical software (SAS version 9.2; SAS Institute, Cary, NC). Statistical significance was assessed using the least significant difference test $(P<0.05)$. Pearson's linear correlation analysis was performed on the gas exchange indexes.

\section{Results}

Plant growth. As shown in Table 2, in the case of the $+\mathrm{K}$ treatments, the grafting combination with the $\mathrm{W}$ genotype tobacco as the rootstock was significantly higher than $\mathrm{Y}$ in terms of the whole plant dry weight, leaf area, and plant height. In addition, there was no significant difference between the same rootstock group (e.g., W and Y/W). The growth parameters of each grafting combination were significantly reduced by potassium starvation, with the dry weight, leaf area, and plant height of the tobacco plants reduced on average by $37.8 \%, 12.5 \%$, and $20.4 \%$, respectively. However, different treatments led to different degrees of decline. Less reduction in dry weight was observed in W (31.1\%) and Y/W (32.2\%) in comparison with W/Y $(44.5 \%)$ and $\mathrm{Y}(61.3 \%)$. The trends in plant height and leaf area were similar. It is worth noting that the growth of the flue-cured tobacco plants in $\mathrm{W} / \mathrm{Y}$ under the condition of $-\mathrm{K}$ was significantly better than that in $\mathrm{Y}$, which differed from that under the condition of $+\mathrm{K}$.

Initial aCtivity of RuBisCO. It can be seen in Fig. 2 that low potassium stress significantly reduced the initial activity of $\mathrm{RuBisCO}$ in each grafting combination. The RuBisCO activity in the grafting combinations with $\mathrm{W}$ as the rootstock decreased by $36.9 \%$, whereas that with $\mathrm{Y}$ as the rootstock decreased by $47.1 \%$, which indicates that the insufficient supply of potassium more greatly affected the initial activity of RuBisCO in the grafting combination of $\mathrm{Y}$ as the rootstock. For the different treatments, the initial activity of RuBisCO at normal and low potassium levels of the grafting combination with $\mathrm{W}$ as the rootstock was significantly higher than that of grafting with $\mathrm{Y}$ as the rootstock, whereas the difference between the same rootstock treatments was not significant.

EFFECTS OF GRAFTING AND POTASSIUM LEVEL ON GAS EXCHANGE IN TOBACCO Leaves. Compared with the $+\mathrm{K}$ treatment, $P_{\mathrm{N}}, E$, and $g_{\mathrm{S}}$ in each grafting combination decreased, respectively, by

Table 2. Effect of two $\mathrm{K}^{+}$level on growth of four tobacco graft combination.

$+\mathrm{K}^{\mathrm{y}}$

\begin{tabular}{|c|c|c|c|c|c|c|}
\hline $\begin{array}{l}\text { Graft } \\
\text { combination }^{z}\end{array}$ & $\begin{array}{l}\text { Whole-plant } \\
\text { dry mass }(\mathrm{g})\end{array}$ & Leaf area $\left(\mathrm{cm}^{2}\right)$ & Plant ht $(\mathrm{cm})$ & $\begin{array}{l}\text { Root surface } \\
\text { area }\left(\mathrm{cm}^{2}\right)\end{array}$ & Root length $(\mathrm{cm})$ & Root vol. $\left(\mathrm{cm}^{3}\right)$ \\
\hline & \multicolumn{6}{|c|}{ mean $\pm \mathrm{SD}^{\mathrm{x}}$} \\
\hline $\mathrm{W}$ & $2.31 \pm 0.11 \mathrm{a}^{\mathrm{w}}$ & $81.92 \pm 4.09 \mathrm{a}$ & $8.72 \pm 0.43 \mathrm{a}$ & $21.93 \pm 1.09 \mathrm{a}$ & $271.09 \pm 13.55 \mathrm{a}$ & $1.42 \pm 0.07 \mathrm{a}$ \\
\hline $\mathrm{W} / \mathrm{Y}$ & $1.48 \pm 0.07 \mathrm{~b}$ & $56.97 \pm 2.84 \mathrm{~b}$ & $7.44 \pm 0.37 \mathrm{~b}$ & $15.34 \pm 0.76 b$ & $195.57 \pm 9.75 b$ & $1.18 \pm 0.06 \mathrm{~b}$ \\
\hline $\mathrm{Y}$ & \multicolumn{6}{|c|}{$-\mathrm{K}$} \\
\hline $\mathrm{Y} / \mathrm{W}$ & $1.46 \pm 0.07 \mathrm{a}$ & $69.86 \pm 3.49 \mathrm{a}$ & $6.61 \pm 0.33 \mathrm{a}$ & $16.75 \pm 0.85 \mathrm{a}$ & $218.98 \pm 10.92 \mathrm{a}$ & $1.06 \pm 0.06 \mathrm{a}$ \\
\hline $\mathrm{W} / \mathrm{Y}$ & $0.86 \pm 0.04 \mathrm{~b}$ & $54.88 \pm 2.74 \mathrm{~b}$ & $6.03 \pm 0.30 \mathrm{~b}$ & $12.42 \pm 0.62 \mathrm{~b}$ & $170.19 \pm 8.56 b$ & $0.82 \pm 0.04 \mathrm{~b}$ \\
\hline Y & $0.61 \pm 0.03 \mathrm{c}$ & $41.11 \pm 2.05 \mathrm{c}$ & $5.17 \pm 0.25 \mathrm{c}$ & $9.28 \pm 0.47 \mathrm{c}$ & $143.33 \pm 7.16 \mathrm{c}$ & $0.63 \pm 0.03 \mathrm{c}$ \\
\hline
\end{tabular}

${ }^{\mathrm{z}} \mathrm{W}=$ 'Wufeng No.2', $\mathrm{Y}=$ 'Yunyan 87 ', $\mathrm{Y} / \mathrm{W}=\mathrm{Y}$ grafted onto $\mathrm{W}, \mathrm{W} / \mathrm{Y}=\mathrm{W}$ grafted onto $\mathrm{Y}$.

${ }^{\mathrm{y}}+\mathrm{K}$, normal supply $\left(5 \mathrm{mmol} \cdot \mathrm{L}^{-1}\right)$ and $-\mathrm{K}$, deficit $\left(0.5 \mathrm{mmol} \cdot \mathrm{L}^{-1}\right)$.

${ }^{\mathrm{x}}$ Mean and SD of six independent replicates.

${ }^{\mathrm{w}}$ Different letters in same potassium supply level within the same column indicate a significant difference $(P<0.05)$. 


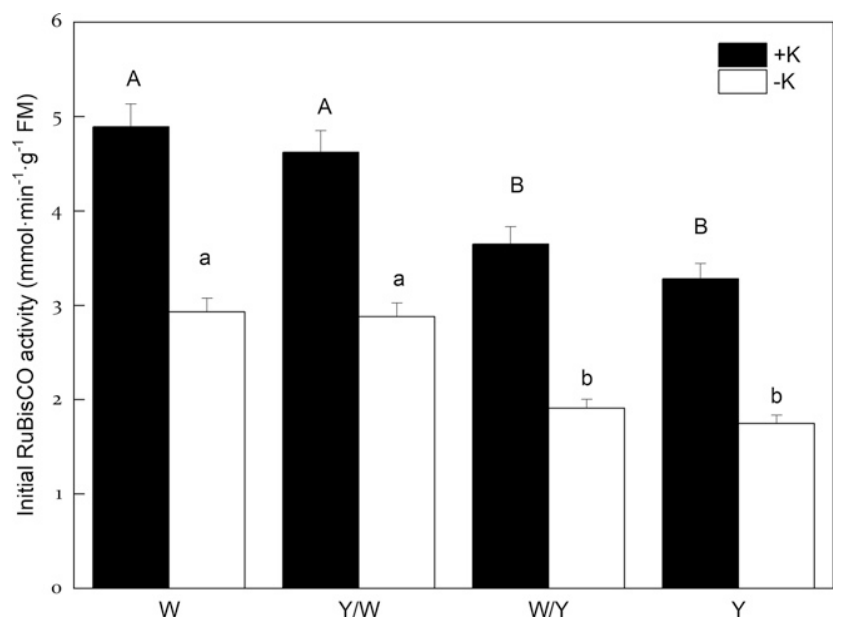

Fig. 2. Effects of grafting on the initial activity of ribulose-1,5-bisphosphate carboxylase-oxygenase $(\mathrm{RuBisCO})$ in the flue-cured tobacco leaves. The tobacco graft combinations included the nongrafted tobacco 'Wufeng No.2' (W) and 'Yunyan $87^{\prime}(\mathrm{Y})$ and the grafted tobacco $\mathrm{Y}$ grafted onto $\mathrm{W}(\mathrm{Y} / \mathrm{W})$ and $\mathrm{W}$ grafted onto $\mathrm{Y}(\mathrm{W} / \mathrm{Y})$. Different uppercase letters denote significant differences $(P<0.05)$ under normal $\mathrm{K}$ levels $\left(5 \mathrm{mmol} \cdot \mathrm{L}^{-1}\right)$, and lowercase letters indicate significant differences $(P<0.05)$ under $\mathrm{K}$ starvation $\left(0.5 \mathrm{mmol} \cdot \mathrm{L}^{-1}\right)$.

$51.8 \%, 24.1 \%$, and $19.0 \%$ with the $-\mathrm{K}$ treatment. At the same time, the $C_{\mathrm{i}}$ increased by $45.1 \%$. As indicated in Fig. 3, each gas exchange parameter of the $\mathrm{W} / \mathrm{Y}$ and $\mathrm{Y}$ grafting combinations was significantly lower than that in $\mathrm{W}$ and $\mathrm{Y} / \mathrm{W}$, except for $C_{\mathrm{i}}$; however, there was no significant difference between the grafting combinations with the same rootstock (e.g., W and $\mathrm{Y} / \mathrm{W}$ ). As for potassium starvation, with the exception that $P_{\mathrm{N}}, E$, and $g_{\mathrm{S}}$ of $\mathrm{W} / \mathrm{Y}$ were significantly higher, and $C_{\mathrm{i}}$ was significantly lower, than $\mathrm{Y}$, the trend among the grafting combinations was basically the same as that of the normal potassium supply. To determine the reasons for the decrease in photosynthesis under low potassium stress, Pearson's linear correlation analysis was carried out on $P_{\mathrm{N}}, C_{\mathrm{i}}, E$, and $g_{\mathrm{S}}$. The analysis results in Table 3

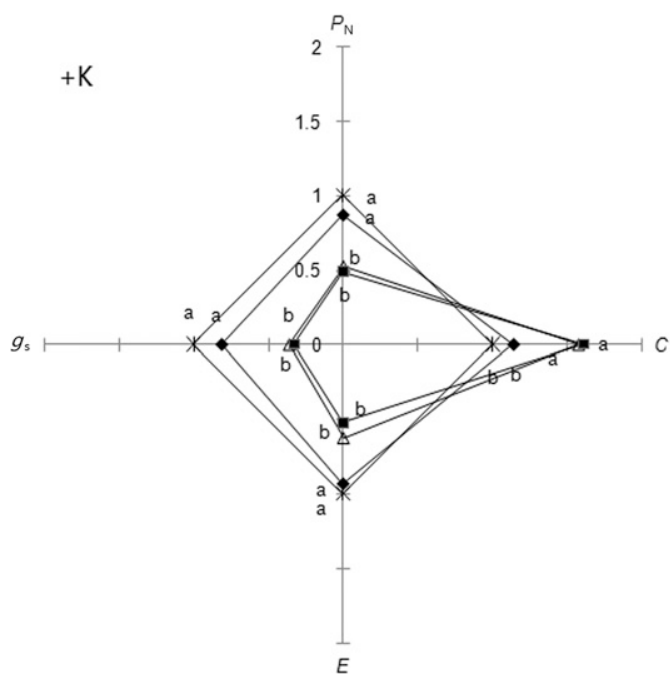

show that $C_{\mathrm{i}}$ was significantly negatively correlated with the other three indicators, suggesting that the decline in $P_{\mathrm{N}}$ rather than the stomatal closure was responsible; otherwise, $C_{\mathrm{i}}$ would have indicated a significantly positive correlation.

EFFECTS OF GRAFTING AND POTASSIUM LEVEL ON PHOTOCHEMICAL EFFICIENCY IN PSII. As indicated in Fig. 4, with the decrease in the potassium supply level, the average values of $\mathrm{F}_{0}$ and NPQ in each grafting combination increased by $15.27 \%$ and $46.7 \%$, respectively, whereas $\mathrm{q}_{\mathrm{p}}$, and $\Phi_{\text {PSII }}$ decreased by $21.3 \%$ and $15.4 \%$, respectively. The difference in $\mathrm{F}_{\mathrm{V}} / \mathrm{F}_{\mathrm{m}}$ between each treatment was not significant. For the different grafting combinations, $\mathrm{F}_{0}$ and $\mathrm{NPQ}$ of $\mathrm{W}$ and $\mathrm{Y} / \mathrm{W}$ were significantly lower than $\mathrm{Y}$ and $\mathrm{W} / \mathrm{Y}$ in the $+\mathrm{K}$ treatment, whereas $\mathrm{q}_{\mathrm{p}}$ and $\Phi_{\mathrm{PSII}}$ in $\mathrm{W}$ and $\mathrm{Y} / \mathrm{W}$ were significantly higher than $\mathrm{Y}$ and $\mathrm{W} / \mathrm{Y}$. The trends in the $-\mathrm{K}$ treatments were similar. It is important to note that the differences between the treatments with the same rootstock were not significant in each chlorophyll fluorescence parameter.

EFFECTS OF GRAFTING AND POTASSIUM LEVEL ON THE EXPRESSION OF CHLOROPHYLL SYNTHASE CODING GENES. Compared with normal potassium supply, the expression level of $C A O 1$ and HemAl in each graft combination was downregulated under potassium deficit. As shown in Fig. 5, regardless of the potassium level, the expression levels of $C A O 1$ and $H e m A l$ were significantly higher in the treatment with $\mathrm{W}$ as the rootstock than in Y. However, there was no difference in the expression levels of $C A O 1$ and HemAl between the treatments with the same rootstock. In other words, grafting significantly alleviated the inhibition of the chlorophyll synthesis of the $\mathrm{Y}$ genotype flue-cured tobacco under low potassium stress.

\section{Discussion}

GRAFTING ALLEVIATED THE INHIBITION OF TOBACCO GROWTH UNDER LOW POTASSIUM STRESS. In recent years, grafting has been successfully applied to mitigate biotic and abiotic and improve mineral element uptake in many plant species (Dong et al.,

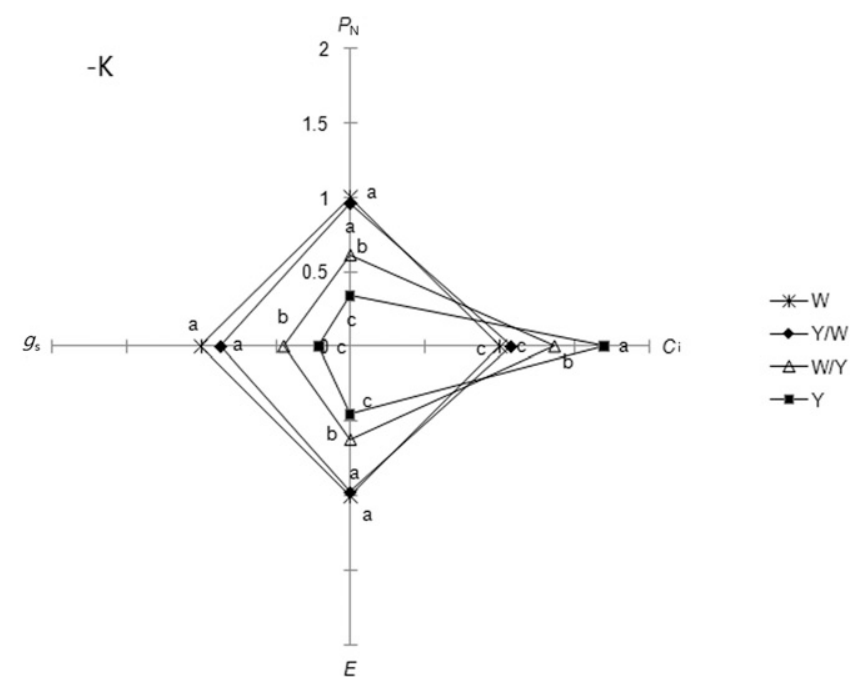

Fig. 3. Effects of grafting and potassium level on gas exchange in tobacco leaves. Different lowercase letters denote significant differences $(P<0.05)\left(C_{\mathrm{i}}=\right.$ intercellular $\mathrm{CO}_{2}$ concentration, $E=$ transpiration rate, $P_{\mathrm{N}}=$ net photosynthetic rate, $g_{\mathrm{S}}=$ stomatal conductance). The tobacco graft combinations included the nongrafted tobacco 'Wufeng No.2' (W) and 'Yunyan 87' (Y) and the grafted tobacco Y grafted onto W (Y/W) and W grafted onto Y (W/Y). To facilitate the comparison of various indicators with large magnitudes of difference in a single figure, the values of each parameter in the $\mathrm{W}$ treatment were converted to 1 , whereas those in the other treatments were proportionally converted based on the $\mathrm{W}$. $+\mathrm{K}$, normal supply $\left(5 \mathrm{mmol} \cdot \mathrm{L}^{-1}\right)$ and $-\mathrm{K}$, deficit $\left(0.5 \mathrm{mmol} \cdot \mathrm{L}^{-1}\right)$. 
Table 3. Pearson's linear correlation coefficient between net photosynthetic rate $\left(P_{\mathrm{N}}\right)$, intercellular $\mathrm{CO}_{2}$ concentration $\left(C_{\mathrm{i}}\right)$, transpiration rate $(E)$, and stomatal conductance $\left(g_{\mathrm{S}}\right)$ of tobacco.

\begin{tabular}{lrcll}
\hline & $P_{\mathrm{N}}$ & $C_{\mathrm{i}}$ & $E$ & $g_{\mathrm{S}}$ \\
\hline$P_{\mathrm{N}}$ & 1 & & & \\
$C_{\mathrm{i}}$ & $-0.95^{*}$ & 1 & & \\
$E$ & $0.93^{*}$ & $-0.98^{* *}$ & 1 & \\
$g_{\mathrm{S}}$ & $0.91^{*}$ & $-0.92^{*}$ & $0.91^{*}$ & 1 \\
\hline
\end{tabular}

*,**Significant at $P<0.05$ or 0.01 , respectively.

2008; Huang et al., 2010; Qin et al., 2014), including tomato, watermelon (Citrullus lanatus), cotton (Gossypium hirsutum), and cucumber (Cucumis sativus). Nevertheless, the effects and mechanisms by which grafting alleviates $\mathrm{K}$ stress in tobacco are largely unknown. The present study shows that tobacco plant growth was obviously weakened under $\mathrm{K}$ starvation but that Kefficient rootstock grafting could alleviate this (Hu et al., 2019). Compared with the $\mathrm{W} / \mathrm{Y}$ and $\mathrm{Y}$ grafting combination, $\mathrm{W}$ and $\mathrm{Y} /$ $\mathrm{W}$ only slightly decreased the plant dry weight, and the trends in plant height and leaf area were similar. Regardless of the K levels, the whole-plant dry weight, height, and leaf area of the $\mathrm{W}$ genotype tobacco were significantly higher than the Y genotype. By grafting, the growth index of the Y genotype tobacco, which used $\mathrm{W}$ as the rootstock, reached the level of the $\mathrm{W}$ genotype tobacco and was significantly higher than the nongrafted original cultivar. Combined with our previous research (Hu et al., 2019), the utility of grafting technology in improving the growth of tobacco plants has been confirmed again in the present study. In addition, as a feedback adjustment from the scion to the rootstock, W also improved the plant growth performance of W/Y. This feedback regulation mechanism in grafting is usually dominated by long-distance signaling, and microRNA or hormonal signals may act as signaling substances (Ferguson and Mathesius, 2003; Lorteau et al., 2001; Wang et al., 2002).

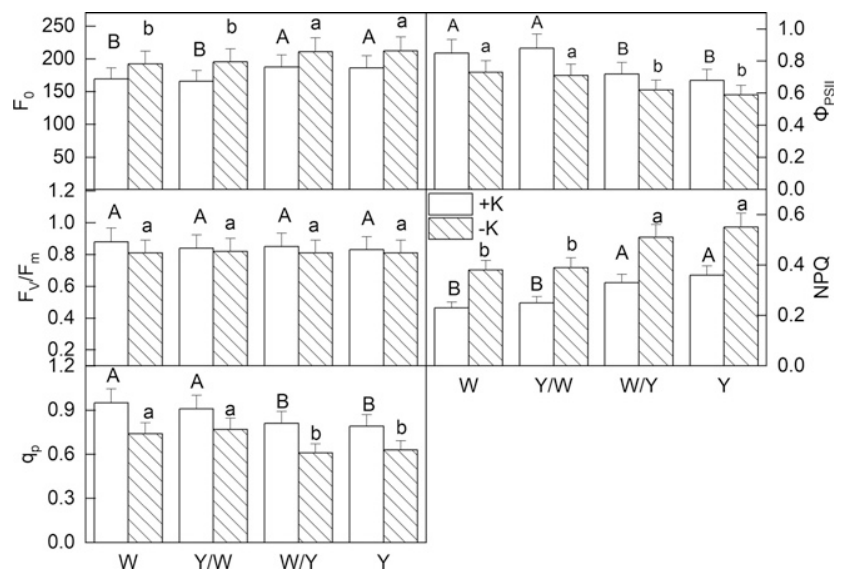

Fig. 4. Effects of grafting and potassium level on the minimal fluorescence yield of the dark-adapted state $\left(\mathrm{F}_{0}\right)$, maximal quantum yield of photosystem II (PSII) photochemistry ( $\mathrm{Fv} / \mathrm{Fm})$, photochemical quenching coefficient $\left(\mathrm{q}_{\mathrm{p}}\right)$, effective quantum yield of PSII photochemistry $\left(\Phi_{\mathrm{PSII}}\right)$, and nonphotochemical quenching (NPQ) in tobacco leaves. The tobacco graft combinations included the nongrafted tobacco 'Wufeng No.2' (W) and 'Yunyan 87' $(\mathrm{Y})$ and the grafted tobacco $\mathrm{Y}$ grafted onto $\mathrm{W}(\mathrm{Y} / \mathrm{W})$ and $\mathrm{W}$ grafted onto $\mathrm{Y}$ $(\mathrm{W} / \mathrm{Y})$. Different uppercase letters denote significant differences $(P<0.05)$ under normal $\mathrm{K}$ levels $\left(5 \mathrm{mmol} \cdot \mathrm{L}^{-1}\right)$, and lowercase letters indicate significant differences $(P<0.05)$ under $\mathrm{K}$ starvation $\left(0.5 \mathrm{mmol} \cdot \mathrm{L}^{-1}\right)$.

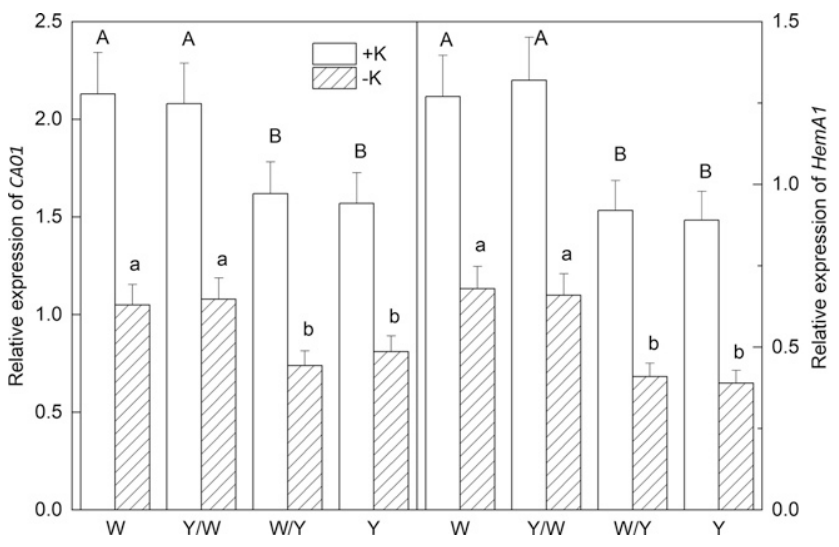

Fig. 5. Relative expression levels of $C A O 1$ and HemA1 in tobacco with two $\mathrm{K}$ supply conditions. The tobacco graft combinations included the nongrafted tobacco 'Wufeng No.2' (W) and 'Yunyan 87' (Y) and the grafted tobacco $\mathrm{Y}$ grafted onto $\mathrm{W}(\mathrm{Y} / \mathrm{W})$ and $\mathrm{W}$ grafted onto $\mathrm{Y}(\mathrm{W} / \mathrm{Y})$. Different uppercase letters denote significant differences $(P<0.05)$ under normal $\mathrm{K}$ levels $\left(5 \mathrm{mmol} \cdot \mathrm{L}^{-1}\right)$, and lowercase letters indicate significant differences $(P<0.05)$ under $\mathrm{K}$ starvation $\left(0.5 \mathrm{mmol} \cdot \mathrm{L}^{-1}\right)$.

Grafting enhances the initial aCtivity of RuBisCO in THE TOBACCO LEAVES. RuBisCO activity includes initial activity and total activity, among which the initial activity represents the activity of ribulose $1-5$ bisphosphate carboxylase, involved in the Calvin cycle. The activity of RuBisCO in the leaves is closely related to the photosynthetic rate. At the same time, it catalyzes the initial reaction of the Calvin cycle and has an important influence on the entire cycle process (Flexas et al., 2016; Niyogi, 2017; Rogers and Humphries, 2000). As the affinity of RuBisCO to $\mathrm{CO}_{2}$ is very low (Jensen, 2000) and the concentration of $\mathrm{CO}_{2}$ in the chloroplasts is insufficient to meet the needs of the assimilation of RuBisCO (Li et al., 2009), the activity of RuBisCO is thus very low under normal conditions. In addition, as a bifunctional enzyme, RuBisCO not only catalyzes RuBP to combine with $\mathrm{CO}_{2}$ for carboxylation reactions but also catalyzes $\mathrm{RuBP}$ to combine with $\mathrm{O}_{2}$ for oxidation reactions, making $\mathrm{CO}_{2}$ and $\mathrm{O}_{2}$ compete for the reaction site of RuBisCO (Salvucci and CraftsBrandner, 2004). The oxidation of RuBisCO is the first step in photorespiration and requires the consumption of electrons. The rate of electron transfer by PSII and the proportion of electron distribution in carboxylation and oxidation directly affect the net photosynthetic rate of the leaves. Studies on different crops have found that potassium application can improve the initial activity of RuBisCO in the leaves (Hu et al., 2016; Peoples and Koch, 1979). In this study, it was found that low potassium stress could significantly reduce the initial activity of $\mathrm{RuBisCO}$ in various grafted tobacco combinations. However, the initial activity of $\mathrm{RuBisCO}$ in the grafting combination with $\mathrm{W}$ as the rootstock was significantly higher than that with $\mathrm{Y}$ as the rootstock at any potassium level. This suggests that the initial RuBisCO activity of the Y genotype tobacco could be improved using $\mathrm{W}$ as the rootstock. Previous studies on rice corroborate our results that both differences in potassium supply and cultivar would cause changes in the initial activity of RuBisCO (Weng et al., 2007; Yang et al., 2004). A study on the effect of potassium starvation on the photosynthetic rate of pecan seedlings found that the regulation of potassium on the ratio of carboxylation and oxidation of RuBisCO may be the main reason that it can affect the initial activity of RuBisCO in the leaves; that is, potassium application 
can increase the proportion of electrons allocated to carboxylation reactions (Jin et al., 2011). Grafting simply meets this requirement from the perspective of improving the potassium absorption efficiency of the tobacco roots (Hu et al., 2020).

REgulation OF POTASSIUM LEVEL ON PHOTOSYNTHETIC EFFICIENCY. The most important effect of potassium on the photosynthetic characteristics of plants relates to two aspects. First, potassium regulates chloroplast morphology and promotes the transport of $\mathrm{CO}_{2}$ from the stomatal cavity to the carboxylation site ( $\mathrm{Lu}$ et al., 2016). Second, potassium promotes the content and activity of RuBisCO to promote $\mathrm{CO}_{2}$ fixation ( $\mathrm{Lu}$ et al., 2017). Some studies suggest that the photosynthetic rate of plant leaves is reduced in the absence of potassium (Chen et al., 2018; Du et al., 2019; Hou et al., 2019; Jin et al., 2011; Kanai et al., 2011), whereas a few reports have pointed out that potassium supply does not significantly improve the leaf photosynthetic rate (Sengupta et al., 1989). For different crops, there must be a threshold for the decrease in photosynthesis caused by potassium deficiency in a specific environment. Therefore, there is currently a different understanding of the effect of potassium on photosynthetic rate (Zorb et al., 2014). Experimental data show that potassium deficiency causes a significant decrease in $P_{\mathrm{N}}, E$, and $g_{\mathrm{S}}$ in flue-cured tobacco leaves, whereas $C_{i}$ increases significantly. According to Pearson's linear correlation analysis results, the reduction in photosynthetic efficiency caused by potassium deficit in this experiment was dominated by nonstomatal factors. This is consistent with our previous study on the leaf gas exchange status of tobacco leaves exposed to drought stress (Hu et al., 2018). Nonstomatal limitation is usually caused by obstacles in carbon assimilation (Weng et al., 2007; Yang et al., 2004) and reducing force (Pinheiro and Chaves, 2011) and also includes the obstruction of the mesophyll layer on $\mathrm{CO}_{2}$ transport (Flexas et al., 2007). The environmental factors that cause nonstomatal limitation generally include low temperature, low light, high $\mathrm{CO}_{2}$ adaptation, and reduction of RuBP content and activity. When the RuBP content and activity were decreased, the ability of $\mathrm{CO}_{2}$ fixation through photosynthesis is significantly weakened. When the stomata are kept open, $\mathrm{CO}_{2}$ accumulates in the mesophyll tissues in large quantities, resulting in increased intercellular $\mathrm{CO}_{2}$ concentration. In this experiment, the lack of potassium caused the synthesis of RuBP to be affected and the Calvin cycle to be blocked, which is also the reason for the nonstomatal limitation. Grafting can effectively mitigate this problem, resulting in the net photosynthetic rate of the $\mathrm{Y} / \mathrm{W}$ treatment being affected much less than that of the nongrafted treatments.

RELATIONSHIP BETWEEN POTASSIUM LEVEL AND PHOTOCHEMICAL EFFICIENCY IN PSII. The results of this experiment show that an increase in $F_{0}$ results in a decrease in nonradiative energy consumption, which causes a decrease in the efficiency of the total reaction center of PSII. $\mathrm{F}_{\mathrm{v}} / \mathrm{F}_{\mathrm{m}}$ of each grafting combination did not change when potassium was scarce, indicating no photoinhibition (Elgersma et al., 2015). At the same time, according to $\mathrm{q}_{\mathrm{p}}$ and NPQ, the proportion of open reaction centers in the PSII system was reduced and the heat dissipation was increased when the potassium level was decreased ( $\mathrm{Lu}$ and Vonshak, 2002). Based on the preceding three points, we can conclude that the decrease in the efficiency of the reaction center of PSII in this experiment was reversible inactivation rather than irreversible damage ( $\mathrm{Hu}$ et al., 2007), which was inseparable from the reduction of potassium levels. An analysis of the chlorophyll fluorescence of cyanobacteria confirms this conclusion (Campbell et al., 1998). It is worth noting that in a study on the relationship between potassium application and the photosynthetic physiology of cotton, the decrease in $\mathrm{F}_{\mathrm{v}} / \mathrm{F}_{\mathrm{m}}$ and $\Phi_{\mathrm{PSII}}$ is the factor that leads to the decline in $P_{\mathrm{N}}(\mathrm{Hu}$ et al., 2016). These results corroborate our research. In this experiment, $\Phi_{\text {PSII }}$ decreased significantly in the absence of potassium, indicating that the reducing force was inhibited, which significantly affected $P_{\mathrm{N}}$ of the leaf. Moreover, an adequate supply of potassium could significantly improve the electron transfer efficiency, which is conducive to the formation of ATP and NADPH, thus improving the reduction force. At the same time, it is evident from the data of this experiment that grafting could effectively improve the electron transfer efficiency of PSII in the flue-cured tobacco leaves caused by the decrease in potassium supply level, which partly explains why the plant growth performance of the $\mathrm{W} / \mathrm{Y}$ treatment was better than the Y treatment.

ANALYSIS OF CAO1 AND HEMAI EXPRESSION LEVEL IN THE LEAVES. Chlorophyll $b$ is formed by the oxidation of chlorophyllide $a$ under the action of chlorophyll $a$ oxygenase (CAO) to form chlorophyllide $b$, which is then formed by esterification (Rudiger, 2002). The gene that encodes the CAO enzyme is $C A O 1$, which is the only gene in the chloroplast that regulates the relative content of chlorophyll $a$ and $b$ (Biswal et al., 2012; Espineda et al., 1999). Glutamyl-transfer RNA reductase (GluTR) is a rate-limiting enzyme for the synthesis of 5-aminolevulinic acid (ALA) and is encoded by the HemA gene family (Goslings et al., 2004). The trial results of transferring the antisense HemAl gene into arabidopsis (Arabidopsis thaliana) indicate that HemAl is the most critical gene regulating GluTR in the HemA family (McCormac et al., 2001). ALA synthesis is the rate-limiting step of the chlorophyll biosynthesis pathway, which means that HemAl dominates the rate of chlorophyll biosynthesis (Zhao et al., 2014). As a cofactor for various enzymes, potassium affects the expression levels of $C A O 1$ and HemAl by participating in multiple enzymatic reactions throughout the photosynthetic pigment synthesis process. Potassium deficiency is closely related to decreased chlorophyll content (Zhao et al., 2001), and our results confirm the previous research conclusion from different perspectives. The expression level of $\mathrm{CAOl}$ and HemAl in each graft combination was downregulated under potassium deficit, but grafting significantly improved the inhibition of chlorophyll synthesis of the $\mathrm{Y}$ genotype flue-cured tobacco under low potassium stress. In this experiment, the difference in expression levels of $C A O 1$ and HemA1 in each treatment originated from two aspects: potassium levels and different flue-cured genotypes. The difference from the grafting combinations with the same scion was significant (e.g., $\mathrm{W}$ and $\mathrm{W} / \mathrm{Y}$ ), suggesting that the dominant factor in the difference in the expression levels between $C A O 1$ and HemA1 is potassium level rather than genotype; that is, grafting improved the synthesis of photosynthetic pigments by improving the potassium absorption capacity of Y-type flue-cured tobacco. At the same time, studies have noted that potassium deficiency also can lead to an increase in the chlorophyll $a$ to chlorophyll $b$ ratio, which is consistent with our experimental results (Jin et al., 2011).

\section{Conclusions}

The main effect of potassium on plant photosynthesis was achieved by changing the efficiency of $\mathrm{CO}_{2}$ assimilation in the 
leaves. In this experiment, the efficiency of photosynthesis in the tobacco leaves and the growth of plants under low potassium stress could be improved by grafting. The reasons can be summarized as follows: 1) In terms of gas exchange of leaves, grafting can alleviate the nonstomatal restriction due to potassium deficiency; and 2) grafting can effectively improve the electron transfer efficiency of PSII in the tobacco leaves under low potassium stress, reduce nonradiation energy dissipation, and enhance the initial activity of RuBisCO.

\section{Literature Cited}

Allen, D.J. and D.R. Ort. 2001. Impacts of chilling temperatures on photosynthesis in warm-climate plants. Trends Plant Sci. 6:36-42, doi: 10.1016/S1360-1385(00)01808-2.

Battie-Laclau, P., J.P. Laclau, C. Beri, L. Mietton, M.R.A. Muniz, B.C. Arenque, M.D.C. Piccolo, L. Jordan-Meille, J.P. Bouillet, and Y. Nouvellon. 2014. Photosynthetic and anatomical responses of Eucalyptus grandis leaves to potassium and sodium supply in a field experiment. Plant Cell Environ. 37:70-81, doi: 10.1111/pce.12131.

Biswal, A.K., G.K. Pattanayak, S.S. Pandey, S. Leelavathi, V.S. Reddy, Govindjee, and B.C. Tripathy. 2012. Light intensity-dependent modulation of chlorophyll $b$ biosynthesis and photosynthesis by overexpression of chlorophyllide a oxygenase in tobacco. Plant Physiol. 159:433-449, doi: 10.1104/pp.112.195859.

Campbell, D., V. Hurry, A.K. Clarke, P. Gustafsson, and G. Oquist. 1998. Chlorophyll fluorescence analysis of cyanobacterial photosynthesis and acclimation. Microbiol. Mol. Biol. Rev. 62:667-683.

Chen, C.T., C.L. Lee, and D.M. Yeh. 2018. Effects of nitrogen, phosphorus, potassium, calcium, or magnesium deficiency on growth and photosynthesis of Eustoma. HortScience 53:795-798, doi: 10.21273/ Hortsci12947-18.

Ding, X.S., J.Z. Liu, N.H. Cheng, A. Folimonov, Y.M. Hou, Y.M. Bao, C. Katagi, S.A. Carter, and R.S. Nelson. 2004. The tobacco mosaic virus $126-\mathrm{kDa}$ protein associated with virus replication and movement suppresses RNA silencing. Mol. Plant Microbe Interact. 17:583-592, doi: 10.1094/Mpmi.2004.17.6.583.

Dong, H.H., Y.H. Niu, W.J. Li, and D.M. Zhang. 2008. Effects of cotton rootstock on endogenous cytokinins and abscisic acid in xylem sap and leaves in relation to leaf senescence. J. Expt. Bot. 59:1295-1304, doi: 10.1093/jxb/ern035.

Du, Q., X.H. Zhao, L. Xia, C.J. Jiang, X.G. Wang, Y. Han, J. Wang, and H.Q. Yu. 2019. Effects of potassium deficiency on photosynthesis, chloroplast ultrastructure, ROS, and antioxidant activities in maize (Zea mays L.). J. Integr. Agr. 18:395-406, doi: 10.1016/ S2095-3119(18)61953-7.

Elgersma, A., K. Soegaard, and S.K. Jensen. 2015. Interrelations between herbage yield, alpha-tocopherol, beta-carotene, lutein, protein, and fiber in non-leguminous forbs, forage legumes, and a grass-clover mixture as affected by harvest date. J. Agr. Food Chem. 63:406-414, doi: 10.1021/jf503658n.

Espineda, C.E., A.S. Linford, D. Devine, and J.A. Brusslan. 1999. The $A t C A O$ gene, encoding chlorophyll a oxygenase, is required for chlorophyll b synthesis in Arabidopsis thaliana. Proc. Natl. Acad. Sci. USA 96:10507-10511, doi: 10.1073/pnas.96.18.10507.

Ferguson, B.J. and U. Mathesius. 2003. Signaling interactions during nodule development. J. Plant Growth Regul. 22:47-72, doi: 10.1007/ s00344-003-0032-9.

Flexas, J., A. Diaz-Espejo, J.A. Berry, J. Cifre, J. Galmes, R. Kaidenhoff, H. Medrano, and M. Ribas-Carbo. 2007. Analysis of leakage in IRGA's leaf chambers of open gas exchange systems: Quantification and its effects in photosynthesis parameterization. J. Expt. Bot. 58:1533-1543, doi: $10.1093 / \mathrm{jxb} / \mathrm{erm} 027$.

Flexas, J., A. Diaz-Espejo, M.A. Conesa, R.E. Coopman, C. Douthe, J. Gago, A. Galle, J. Galmes, H. Medrano, M. Ribas-Carbo, M. Tomas, and U. Niinemets. 2016. Mesophyll conductance to $\mathrm{CO}_{2}$ and
Rubisco as targets for improving intrinsic water use efficiency in C-3 plants. Plant Cell Environ. 39:965-982, doi: 10.1111/pce.12622.

Gao, Q.H., Y. Wu, S.S. Jia, S.C. Huang, and X.M. Lu. 2016. Effect of rootstock on the growth, photosynthetic capacity and osmotic adjustment of eggplant seedlings under chilling stress and recovery. Pak. J. Bot. 48:461-468.

Gerardeaux, E., L. Jordan-Meille, J. Constantin, S. Pellerin, and M. Dingkuhn. 2010. Changes in plant morphology and dry matter partitioning caused by potassium deficiency in Gossypium hirsutum (L.). Environ. Exp. Bot. 67:451-459, doi: 10.1016/j.envexpbot.2009.09.008.

Goslings, D., R. Meskauskiene, C.H. Kim, K.P. Lee, M. Nater, and K. Apel. 2004. Concurrent interactions of heme and FLU with Glu tRNA reductase (HEMA1), the target of metabolic feedback inhibition of tetrapyrrole biosynthesis, in dark- and light-grown Arabidopsis plants. Plant J. 40:957-967, doi: 10.1111/j.1365-313X.2004.02262.x.

Hou, W.F., M. Trankner, J.W. Lu, J.Y. Yan, S.Y. Huang, T. Ren, R.H. Cong, and X.K. Li. 2019. Interactive effects of nitrogen and potassium on photosynthesis and photosynthetic nitrogen allocation of rice leaves. BMC Plant Biol. 19, doi: 10.1186/S12870-019-1894-8.

Hu, W., Q. Di, Z.J. Wang, Y.M. Zhang, J. Zhang, J. Liu, and X.J. Shi. 2019. Grafting alleviates potassium stress and improves growth in tobacco. BMC Plant Biol. 19, doi: 10.1186/S12870-019-1706-1.

Hu, W., Q. Di, J. Zhang, J. Liu, and X.J. Shi. 2020. Response of grafting tobacco to low potassium stress. BMC Plant Biol. 20, doi: 10.1186/s12870-020-02481-6.

Hu, W., N. Jiang, J.S. Yang, Y.L. Meng, Y.H. Wang, B.L. Chen, W.Q. Zhao, D.M. Oosterhuis, and Z.G. Zhou. 2016. Potassium (K) supply affects $\mathrm{K}$ accumulation and photosynthetic physiology in two cotton (Gossypium hirsutum L.) cultivars with different $\mathrm{K}$ sensitivities. Field Crops Res. 196:51-63, doi: 10.1016/j.fcr.2016.06.005.

Hu, W., S.B. Tian, Q. Di, S.H. Duan, and K. Dai. 2018. Effects of exogenous calcium on mesophyll cell ultrastructure, gas exchange, and photosystem II in tobacco (Nicotiana tabacum Linn.) under drought stress. Photosynthetica 56:1204-1211, doi: 10.1007/s11099-018-0822-8.

Hu, Y.B., G.Y. Sun, and X.C. Wang. 2007. Induction characteristics and response of photosynthetic quantum conversion to changes in irradiance in mulberry plants. J. Plant Physiol. 164:959-968, doi: 10.1016/j.jplph.2006.07.005.

Huang, W.J., S.H. Liao, H.Y. Lv, A.B.M. Khaldun, and Y. Wang. 2015. Characterization of the growth and fruit quality of tomato grafted on a woody medicinal plant, Lycium chinense. Scientia Hort. 197:447-453, doi: 10.1016/j.scienta.2015.10.005.

Huang, Y., Z.L. Bie, S.P. He, B. Hua, A. Zhen, and Z.X. Liu. 2010. Improving cucumber tolerance to major nutrients induced salinity by grafting onto Cucurbita ficifolia. Environ. Exp. Bot. 69:32-38, doi: 10.1016/j.envexpbot.2010.02.002.

Jang, Y., B. Mun, K. Do, Y. Um, and C. Chun. 2014. Effects of photosynthetic photon flux and carbon dioxide concentration on the photosynthesis and growth of grafted pepper transplants during healing and acclimatization. Hort. Environ. Biotechnol. 55:387-396, doi: 10.1007/s13580-014-0221-4.

Jensen, R.G. 2000. Activation of Rubisco regulates photosynthesis at high temperature and $\mathrm{CO}_{2}$. Proc. Natl. Acad. Sci. USA 97:12937-12938, doi: 10.1073/pnas.97.24.12937.

Jin, S.H., J.Q. Huang, X.Q. Li, B.S. Zheng, J.S. Wu, Z.J. Wang, G.H. Liu, and M. Chen. 2011. Effects of potassium supply on limitations of photosynthesis by mesophyll diffusion conductance in Carya cathayensis. Tree Physiol. 31:1142-1151, doi: 10.1093/treephys/tpr095. Kanai, S., R.E. Moghaieb, H.A. El-Shemy, R. Panigrahi, P.K. Mohapatra, J. Ito, N.T. Nguyen, H. Saneoka, and K. Fujita. 2011. Potassium deficiency affects water status and photosynthetic rate of the vegetative sink in green house tomato prior to its effects on source activity. Plant Sci. 180:368-374, doi: 10.1016/j.plantsci.2010.10.011.

Kim, T.H., M. Bohmer, H.H. Hu, N. Nishimura, and J.I. Schroeder. 2010. Guard cell signal transduction network: Advances in understanding abscisic acid, $\mathrm{CO} 2$, and $\mathrm{Ca} 2+$ signaling. Annu. Rev. Plant Biol. 61:561-591, doi: 10.1146/annurev-arplant-042809-112226. 
Li, Y., Y.X. Gao, X.M. Xu, Q.R. Shen, and S.W. Guo. 2009. Lightsaturated photosynthetic rate in high-nitrogen rice (Oryza sativa L.) leaves is related to chloroplastic $\mathrm{CO} 2$ concentration. J. Expt. Bot. 60:2351-2360, doi: 10.1093/jxb/erp127.

Livak, K.J. and T.D. Schmittgen. 2001. Analysis of relative gene expression data using real-time quantitative PCR and the 2(T)(-Delta Delta C) method. Methods 25:402-408, doi: 10.1006/meth.2001.1262.

Lorteau, M.A., B.J. Ferguson, and F.C. Guinel. 2001. Effects of cytokinin on ethylene production and nodulation in pea (Pisum sativum) cv. Sparkle. Physiol. Plant. 112:421-428, doi: 10.1034/j.13993054.2001.1120316.x.

Lu, C. and A. Vonshak. 2002. Effects of salinity stress on photosystem II function in cyanobacterial Spirulina platensis cells. Physiol. Plant. 114:405-413, doi: 10.1034/j.1399-3054.2002.1140310.x.

Lu, Z.F., J.W. Lu, Y.H. Pan, P.P. Lu, X.K. Li, R.H. Cong, and T. Ren. 2016. Anatomical variation of mesophyll conductance under potassium deficiency has a vital role in determining leaf photosynthesis. Plant Cell Environ. 39:2428-2439, doi: 10.1111/pce.12795.

Lu, Z.F., Y.H. Pan, W.S. Hu, R.H. Cong, T. Ren, S.W. Guo, and J.W. Lu. 2017. The photosynthetic and structural differences between leaves and siliques of Brassica napus exposed to potassium deficiency. BMC Plant Biol. 17, doi: 10.1186/S12870-017-1201-5.

McCormac, A.C., A. Fischer, A.M. Kumar, D. Soll, and M.J. Terry. 2001. Regulation of HEMA1 expression by phytochrome and a plastid signal during de-etiolation in Arabidopsis thaliana. Plant J. 25:549-561, doi: 10.1046/j.1365-313x.2001.00986.x.

Niyogi, K.K. 2017. Editorial overview: Physiology and metabolism: Light responses from photoreceptors to photosynthesis and photoprotection. Curr. Opin. Plant Biol. 37:Iv-Vi, doi: 10.1016/j.pbi.2017.05.009.

Peoples, T.R. and D.W. Koch. 1979. Role of potassium in carbon-dioxide assimilation in Medicago sativa L. Plant Physiol. 63:878-881, doi: 10.1104/Pp.63.5.878.

Pettigrew, W.T. 1999. Potassium deficiency increases specific leaf weights and leaf glucose levels in field-grown cotton. Agron. J. 91:962-968, doi: 10.2134/agronj1999.916962x.

Pinheiro, C. and M.M. Chaves. 2011. Photosynthesis and drought: Can we make metabolic connections from available data? J. Expt. Bot. 62:869-882, doi: 10.1093/jxb/erq340.

Qin, Y.G., C.Q. Yang, J.L. Xia, J. He, X.L. Ma, C.Y. Yang, Y.X. Zheng, X. Lin, Z.Q. He, Z. Huang, and Z.S. Yan. 2014. Effects of dual/threefold rootstock grafting on the plant growth, yield and quality of watermelon. Not. Bot. Horti Agrobot. Cluj-Napoca 42:495-500, doi: 10.15835/nbha4229701.

Quentin, A.G., D.C. Close, L.M.H.P. Hennen, and E.A. Pinkard. 2013. Down-regulation of photosynthesis following girdling, but contrasting effects on fruit set and retention, in two sweet cherry cultivars. Plant Physiol. Biochem. 73:359-367, doi: 10.1016/j.plaphy.2013.10.014.

Rahmatian, A., M. Delshad, and R. Salehi. 2014. Effect of grafting on growth, yield and fruit quality of single and double stemmed tomato plants grown hydroponically. Hort. Environ. Biotechnol. 55:115-119, doi: 10.1007/s13580-014-0167-6.

Rogers, A. and S.W. Humphries. 2000. A mechanistic evaluation of photosynthetic acclimation at elevated $\mathrm{CO}_{2}$. Glob. Change Biol. 6:1005-1011, doi: 10.1046/j.1365-2486.2000.00375.x.

Rudiger, W. 2002. Biosynthesis of chlorophyll b and the chlorophyll cycle. Photosynth. Res. 74:187-193, doi: 10.1023/A:1020959610952.

Salvucci, M.E. and S.J. Crafts-Brandner. 2004. Inhibition of photosynthesis by heat stress: The activation state of Rubisco as a limiting factor in photosynthesis. Physiol. Plant. 120:179-186, doi: 10.1111/ j.0031-9317.2004.0173.x.

Sengupta, A., G.A. Berkowitz, and P.A. Pier. 1989. Maintenance of photosynthesis at low leaf water potential in wheat - Role of potassium status and irrigation history. Plant Physiol. 89:1358-1365, doi: 10.1104/Pp.89.4.1358.

Wang, N., H.B. Hua, A.E. Eneji, Z.H. Li, L.S. Duan, and X.L. Tian. 2012. Genotypic variations in photosynthetic and physiological adjustment to potassium deficiency in cotton (Gossypium hirsutum). J. Photochem. Photobiol. B 110:1-8, doi: 10.1016/j.jphotobiol.2012.02.002.

Wang, Y.H., D.F. Garvin, and L.V. Kochian. 2002. Rapid induction of regulatory and transporter genes in response to phosphorus, potassium, and iron deficiencies in tomato roots. Evidence for cross talk and root/ rhizosphere-mediated signals. Plant Physiol. 130:1361-1370, doi: $10.1104 / \mathrm{pp} .008854$.

Weng, X.Y., C.J. Zheng, H.X. Xu, and J.Y. Sun. 2007. Characteristics of photosynthesis and functions of the water-water cycle in rice $(\mathrm{Or}$ yza sativa) leaves in response to potassium deficiency. Physiol. Plant. 131:614-621, doi: 10.1111/j.1399-3054.2007.00978.x.

Yang, X.E., J.X. Liu, W.M. Wang, Z.Q. Ye, and A.C. Luo. 2004. Potassium internal use efficiency relative to growth vigor, potassium distribution, and carbohydrate allocation in rice genotypes. J. Plant Nutr. 27:837-852, doi: 10.1081/Pln-120030674.

Zhang, G.H. and H.C. Guo. 2019. Effects of tomato and potato heterografting on photosynthesis, quality and yield of grafted parents. Hortic. Environ. Biotechnol. 60:9-18, doi: 10.1007/ s13580-018-0096-x.

Zhao, A.G., Y. Fang, X.M. Chen, S. Zhao, W. Dong, Y.J. Lin, W.M. Gong, and L. Liu. 2014. Crystal structure of Arabidopsis glutamyl-tRNA reductase in complex with its stimulator protein. Proc. Natl. Acad. Sci. USA 111:6630-6635, doi: 10.1073/ pnas. 1400166111.

Zhao, D.L., D.M. Oosterhuis, and C.W. Bednarz. 2001. Influence of potassium deficiency on photosynthesis, chlorophyll content, and chloroplast ultrastructure of cotton plants. Photosynthetica 39:103-109, doi: 10.1023/A:1012404204910.

Zorb, C., M. Senbayram, and E. Peiter. 2014. Potassium in agriculture - Status and perspectives. J. Plant Physiol. 171:656-669, doi: 10.1016/j.jplph.2013.08.008. 